\title{
La ambigüedad como estrategia en el prólogo de la novela francesa del XVIII ${ }^{1}$
}

\author{
Mercedes NAVARRO CAMEO \\ Universidad Nacional de Educación a Distancia \\ meyes@telefonica.net
}

Recibido: $30 / 10 / 2010$

Aceptado: $20 / 12 / 2010$

\section{Resumen}

La práctica de la ambigüedad en el prólogo de la novela francesa del XVIII responde a unos propósitos pragmáticos. Para ello, los autores adoptan una modalización discursiva ambigua, que es estilística y literaria, y se define como una estrategia autorial muy eficaz para hacer pasar las obras por lo que no son, para prevenir, esquivar y solventar todos los dilemas y conflictos, éticos y estéticos, que sufre este sospechoso género novelesco. Allí donde aparece un discurso ambiguo, se revela la existencia de un conflicto: interno o externo, literario o social, individual o colectivo. También la intención de resolverlo, ya de modo preventivo, ya provocador. Finalmente, este análisis de la ambigüedad demuestra ser un instrumento privilegiado para reconstruir la historia y evolución de la novela a lo largo del siglo.

Palabras clave: novela francesa del siglo XVIII, estrategias prefaciales, ambigüedad literaria

\section{L'ambiguïté en tant que stratégie préfacielle dans le roman français du XVIII ${ }^{\mathrm{ème}}$ siècle}

\begin{abstract}
Résumé
L'ambiguité, en tant que stratégie préfacielle dans le roman français du dix-huitième siècle, répond à des objectifs pragmatiques. Pour cela, les auteurs ont recours à une modalisation discursive ambiguë, stylistique et littéraire, qui prétend à une stratégie autoriale très efficace pour faire passer les œuvres pour ce qu'elles ne sont pas, afin de prévenir, de se dérober et de résoudre les dilemmes et les conflits éthiques et esthétiques posés par ce genre romanesque soumis à caution. En effet, un discours ambigu est toujours la preuve de l'existence d'un conflit : interne ou externe, à l'échelle de l'individuel ou du collectif. Mais aussi, parfois, de la volonté de le résoudre, soit en le prévenant, soit par la provocation. Cette analyse de l'ambiguïté préfacielle, enfin, montre qu'elle est un instrument de premier ordre pour reconstituer l'histoire et l'évolution du roman au XVIIIème siècle.
\end{abstract}

Mots clés: roman français du XVIIIème siècle, stratégies préfacielles, ambiguïté littéraire.

\footnotetext{
${ }^{1}$ Este estudio acerca de la ambigüedad en el prólogo de la novela francesa del XVIII forma parte de la Tesis Doctoral defendida ante un Tribunal compuesto por los Profs. Yllera, Goulemot, Delon, Vázquez y Popa, con la denominación de Técnicas, Modelos y Análisis de la Literatura Prefacial de la Novela Francesa del Siglo XVIII (2010), dirigida por el Prof. Velázquez, con la calificación de Sobresaliente cum Laude por unanimidad.
} 


\title{
Ambiguity as a Literary Strategy in the Preface of Eighteenth Century French Novels
}

\begin{abstract}
The frequent and conscious use of ambiguity in the preface of the eighteenth century French novel reflects a pragmatic purpose and a very efficient authorial strategy to disguise or conceal the true nature of the oeuvre. It also helps to prevent, avoid or solve any ethical or aesthetic conflicts that this highly suspicious literary genre would face in the winding and treacherous road between authors and readers. Very often the recourse to ambiguity is a tell-tale sign of a conflict which the author intends to address and hopefully solve. The conflict can be very diverse: internal or external, literary or social, collective or individual. Its analysis is an exceptionally useful tool to explore the evolution and the intimate history of the French novel during this century.
\end{abstract}

Key words: french novel in eighteenth century, prefatorial strategies, literary ambiguity.

\section{Referencia normalizada}

Navarro Cameo, M. (2012) "La ambigüedad como estrategia en el prólogo de la novela francesa del XVIII". Thélème, Vol. 27, 291-319.

Sumario: A. Ambigüedad en torno a quién habla en el prólogo y qué relación guarda el prologuista con respecto a la obra. B. La ambigüedad en la declaración de intenciones. C. La ambigüedad en la definición genérica. D. La ambigüedad en el contrato de ficción. Conclusión.

El Diccionario de la R. A. E. define lo ambiguo como aquello que puede entenderse de varios modos o admitir distintas interpretaciones, y dar, por consiguiente, motivo a dudas, incertidumbres o confusión. Su segunda acepción añade: Dícese de quien con sus palabras o comportamiento vela o no define claramente sus actitudes. En ambas definiciones subyace una connotación negativa del concepto, por generar incertidumbre o confusión, o por suponer un ocultamiento de las actitudes o intenciones reales de quienes la practican. Idea que se arrastra desde la antigua retórica clásica y que todavía subsiste en nuestros días.

En términos generales, y en un sentido lingüístico, parafraseando a Chomsky, se admite que una proposición genera ambigüedad cuando diversas representaciones profundas se proyectan en una única representación superficial: así, si una proposición contiene una única estructura subyacente, no es ambigua, mientras que si contiene dos o más, sí que lo es, disponiendo entonces de dos o más lecturas diferentes, todas ellas posibles pero incompatibles entre sí. En cuanto a las manifestaciones en que se produce, está claro que la ambigüedad puede ser también funcional, morfológica o sintáctica ${ }^{2}$.

\footnotetext{
${ }^{2}$ Con respecto a las aproximaciones lingüísticas, cabe reseñar que D. Madelénat la define como
} 
La ambigüedad puede emanar de una carencia formal o de un fallo enunciativo no buscado por quien la practica. Está claro que, en algunos tipos de discursos, resulta ser un aspecto no previsto o no resuelto por su emisor. Sin embargo, y éste es el aspecto que me interesa destacar, la ambigüedad puede ser un efecto plenamente buscado y consciente por parte de quien la produce y tratarse de una licencia lúdica, de un alarde de ingenio o simplemente de una picaresca estilística. Y es preciso subrayar que su desarrollo a menudo alcanza un grado mayor de sofisticación cuando responde a propósitos artísticos o pragmáticos.

En el marco literario, destacan las aportaciones de W. Empson, quien considera a la ambigüedad como una peculiar dilatación semántica del lenguaje poético, que no coincide con el simple significado literal. Con lo cual, viene a coincidir con la connotación o con la polisemia o, lo que viene a resultar lo mismo, con la complejidad y la hipersemantización propias de los signos literarios. En este sentido el lenguaje que se denomina figurado es esencialmente polisémico, ya que lleva el sentido más allá de la referencia inmediata. Como señala $\mathrm{Cl}$. Gutiérrez, se trata de una cuestión muy compleja, entendiendo que

la ambigüedad es inherente a toda comunicación, [que] toda comunicación interesante ocurre en lenguajes con un grado mayor o menor de ambigüedad, [y que] para asegurar la adecuada inteligencia recíproca de mensajes se requiere algo más que simples correspondencias de símbolo a símbolo entre emisor y receptor [...], una cierta correlación entre los universos de significación implicados por cada grupo de símbolos... [y entendiendo que dicha correlación jamás aparece en estado puro ni es sencilla] porque puede implicar rompimiento de esquemas mentales de los comunicantes, al actuar sobre ellos la presión de anomalías sistemáticas o de presencias renovadoras del lenguaje implícitas en las angustias e inquietudes de los participantes... [de manera que su resultado se traduce en que se ve aparecer] un campo nuevo de significaciones, determinados por la interacción de materia semántica de dos universos de discurso que antes existieron de forma separada (Gutiérrez, 1977).

\footnotetext{
"ese carácter que atribuimos a una realidad o a un signo cuando no podemos atribuirles nítidamente funciones o sentidos ya repertoriados y delimitados por la situación contextual". J. I. Velázquez señala que los "Diccionarios lingüísticos nos hablan de aquello que es susceptible de recibir distintas interpretaciones [...] de aquello que forma parte de distintas categorías e, incluso, de aquello que carece de claridad e inquieta", subrayando que, para Dubois, indica "la propiedad de un signo con distintos sentidos", para, a continuación, referir las distintas clasificaciones realizadas a partir de Bally, Bréal, Lallot, Dauzat, Ruwet, Bonnard, Le Galliot o Landheer: ambigüedades fonológicas, debidas a la homonimia léxica, las propias de las relaciones sintácticas, polisémicas, homofónicas, por indeterminación, por acumulación, la redundante, la anataclasis... Jakobson, quien la definía en 1963 como una "propiedad intrínseca, inalienable, de todo discurso centrado en sí mismo", al analizar su función poética, debe tener muy en cuenta la ambigüedad, cuando señala: "la supremacía de la función poética sobre la función referencial no anula la referencia (la denotación) pero la convierte en ambigua". Pues bien, todas las clasificaciones reseñadas toman en consideración los componentes sintáctico, fonológico y semántico, pero vienen a concluir en sus insuficiencias teóricas y en la imposibilidad de establecer un repertorio que dé cabida a todos los usos de un recurso cuya riqueza y variedad desborda ampliamente todos los intentos de clasificación estricta. (Velázquez, 2005a).
} 
No faltan los estudios cuya aproximación crítica considera la ambigüedad como una cualidad estilística. En su aplicación a la escritura de La double inconstance (1723) de Marivaux, Velázquez prueba cómo constituye la clave de esta obra y resulta, por ello, especialmente rica en su estructuración:

On n'insistera jamais assez sur la valeur stylistique de l'ambiguïté dans la création littéraire, fondée sur l'évidence même de son caractère productif, en rupture avec cette approche négative qui ne la voit que comme un défaut à supprimer par sa mise en cause non seulement du message mais aussi de l' efficacité du système, et cela depuis Aristote et la troisième règle de sa Rhétorique jusqu'aux postulats contemporains de la communication (Velázquez, 2008: 77).

De acuerdo con él, considero la ambigüedad como una práctica estratégica que afecta a la producción del texto, en el marco de un plan consciente y preconcebido por el autor, con unos fines pragmáticos:

De même, il est hors de doute que son usage n'est pas forcément lié à l'expression inconsciente du créateur -encore que lorsqu'il n'en est pas ainsi, cet usage l'engage au-delà de lui-même-. Car, dans ce cas il s'agirait d'un trait marquant le créateur, et non plus tellement le système expressif. Bien au contraire, ce classement que j'ai proposé ailleurs des écritures de l'ambiguïté a pour point de départ un usage conscient de l'expression ambiguë comme le seul susceptible de produire des effets bien précis sur le lecteur. Ce qui me permet de dire qu'il n'existe pas d'œuvres ambiguës mais des auteurs qui l'intègrent dans leurs options expressives et s'en servent pour établir leurs discours ${ }^{3}$ (Velázquez, 2008 : 77).

Pues bien, este estudio se centra en el valor estratégico del discurso ambiguo de los prologuistas de novelas del siglo XVIII francés, como práctica discursiva consciente y premeditada, cuya modalización es todo un recurso estilístico y literario y con una clara orientación pragmática, y cuya sutileza, objetivos y resultados es preciso tomar en consideración y valorar.

\footnotetext{
${ }^{3}$ Muy en síntesis, cabe señalar que este autor establece el marco de sus análisis sobre la ambigüedad en el desarrollo de siete modelos (que nada tienen que ver con los de Empson) de escritura: la onírica, la propia de lo "fantástico mental", la policíaca, la relacionada con la expresión del erotismo, la de determinados recursos de comicidad, la de la búsqueda formal y la de la búsqueda de la identidad, y las relaciona con tres temas recurrentes: el propio de una temática recurrente "de aquellas figuras que subvierten los elementos sobre los que se basa cualquier forma de identidad posible, es decir, las coordenadas temporales y espaciales, a partir del hecho primario según el cual lo que mejor nos define es el espacio que ocupamos en cada momento". También, "las figuras caracterizadas por lo irracional, es decir, aquellas que desbordan las formas de conocimiento y de representación basadas en la razón y", finalmente, "las figuras conflictivas de la evasión y la búsqueda... en un abanico que comprende tanto el trayecto de escritura como el descenso en sí mismo", en relación con un conjunto de "constelaciones": la metamorfosis, los conflictos binarios, todas las manifestaciones relacionadas con la máscara, el carnaval, el malditismo, el Doble, Eros y Thanatos, el narcisismo, éxtasis, sepulcro y telurismo, la huída, la errancia, la disolución y el no-ser, las microcosmizaciones y las duplicaciones, los refugios y el misticismo, así como su relación con el régimen nocturno, en los términos expuestos por G. Durand (Cf. Velázquez, 2008 : 78).
} 
Así pues, cuando me refiero a la ambigüedad que presentan estos prólogos, aludo a la complejidad del contenido semántico del discurso o, más bien, a la multiplicidad de los planos en que podría interpretarse el contenido de un mismo prólogo. Es ésta una muy eficaz estrategia de los autores, destinada a cumplir varias funciones mediante un mismo enunciado. En otros términos, curiosamente, se trata de una aplicación de lo que W. Empson vendría a indicar en el propio prólogo a Seven types of Ambiguity: "por ambigüedad, entiendo lo que me apetece entender" (Empson, 1949: viii).

Tal vez ésta sea la razón fundamental de la actitud enunciativa ambigua de buena parte de estos autores del siglo XVIII en sus prólogos: que cada lector interprete lo que le apetezca, o lo que más desee, o lo que menos conflictos le produzca, con el fin de satisfacer a los distintos lectores mediante un único enunciado - lo cual implica, desde luego, ese principio básico de la literatura contemporánea, que exige la participación del lector en el proceso de recreación o actualización de la obra que se contiene en cada nueva lectura. Y, sin duda, a ello apunta la modalización ambigua de Roussseau en su primer prólogo a La Nouvelle Héloïse: "[...] Voilà tout ce que je puis dire. Que chacun pense comme il lui plaira". Unos términos que no están demasiado alejados de los que utilizaría W. Empson al definir la ambigüedad del modo siguiente:

Una ambigüedad, en el habla común, significa algo muy marcado, y por regla, ingenioso o falso. Propongo emplear el término en un sentido amplio, y me parecerá pertinente para mi tema todo matiz verbal, por ligero que sea, que permita reacciones alternas a la misma porción del lenguaje 5 (Empson, 1949: viii).

Aunque el estudio de Empson se centra en el análisis de la poesía, el hecho de que su posición crítica privilegie una lectura de la misma como exploración de los conflictos que subyacen en el creador parece también idóneo, ya que estos prólogos también traducen muchos de los conflictos de sus autores y de la novela que practican, y la ambigüedad de su escritura prefacial resulta en ocasiones el mejor indicio de conflicto. Pues bien, del mismo modo que Empson, mis análisis tienen por objetivo actualizar, a modo de recomposición de un rompecabezas, los distintos vectores de presión sobre los autores que encuentran en el recurso a la ambigüedad la mejor estrategia para referirlos o enfrentarse con ellos. Lo cual me permite esta-

\footnotetext{
${ }^{4}$ Literalmente: "[...] I claimed at the start that I would use the term "ambiguity" to mean anything I liked". Dicho autor, muy en síntesis, distingue las variantes lógicas, psicológicas, formales, metafóricas, metonímicas, contradictorias en el SE e impresionistas. La versión en español figura también en la Bibliografía.

${ }^{5}$ Textualmente: "any verbal nuance, however slight, which gives room for alternative reactions to the same piece of language".
} 
blecer, muy en síntesis, que las claves de las modalizaciones ambiguas se agrupan en torno a cuatro cuestiones principales:

a) Quién habla en el prólogo y qué relación guarda el prologuista hacia la obra,

b) La declaración de intenciones,

c) La definición genérica, y

d) El contrato de ficción.

Las tres últimas cuestiones van referidas a dos de las principales funciones del prólogo autorial original, siendo la definición genérica una variante de la declaración de intenciones, y vendrían a responder a la cuestión de cómo debe leerse la obra. Sin embargo, la primera de las cuestiones se refiere al status del prologuista, a quién habla en el prólogo y qué función desempeña con respecto al texto, y en qué régimen de verdad se presentan sus declaraciones. Conviene no perder de vista este elemento, ya que no debemos olvidar que aunque el emisor del prólogo es siempre el autor -salvo en los prólogos alógrafos reales-, el locutor de los prólogos puede simular ser otro, o declarar de modo ficticio o apócrifo -es decir, falso- que no es el autor del texto al que se refiere (o que dicho texto no es una ficción o un cuadro de vicios, etc.), pero no puede obviarse que una cosa es lo que los autores o prologuistas pretendan o simulen -o simulen pretender-, y otra bien distinta que consigan engañar a los receptores o lectores de sus prólogos - o que éstos actúen como si desearan ser engañados. En este sentido, la tipología funcional de Genette ${ }^{6}$, organizada en torno a los criterios de lugar, momento y tipo de prologuista, resulta muy eficaz. Sus criterios básicos contemplan seis categorías principales que a su vez recogen otras seis subtipologías. Pues bien, el estudio del corpus de prólogos realizado y su peculiar naturaleza me obligan a añadir una séptima tipología principal, la del prólogo ambiguo, que nada tiene que ver con el problema de las hibridaciones de prólogos y se centra en consideraciones muy distintas a las planteadas por esta peculiaridad prefacial, dado que muy a menudo escapan a una única definición por entrar en contradicción con ella misma, o pudiendo responder a varias a la vez, o a ninguna de las establecidas por Genette.

\footnotetext{
${ }^{6}$ Me refiero a una de las tipificaciones que del prólogo lleva a cabo Genette en Seuils. Para este especialista del paratexto es el aspecto funcional del prólogo su rasgo más definitorio, y de sus distintas funciones se desprenden los distintos tipos de prólogo y viceversa. Su tipologia funcional está determinada por los distintos tipos de emisores del prólogo y por los parámetros de tiempo y lugar. Ésta recoge seis tipos fundamentales: prólogo autorial original; epílogo autorial original; prólogo autorial ulterior; prólogo o epílogo autorial tardío; prólogo alógrafo auténtico (que incluye como variante el subtipo del actorial auténtico), y, en sexto lugar, el prólogo ficcional, que a su vez reagrupa las subtipologías ficcionales de los prólogos autorial denegativo; autorial ficticio; actorial ficticio; alógrafo ficticio; autorial apócrifo; actorial apócrifo y alógrafo apócrifo, para concluir con una subtipología de prólogos especulares o miroirs.
} 


\section{A. Ambigüedad en torno a quién habla en el prólogo y qué relación guarda el prologuista con respecto a la obra}

Del conjunto de prólogos de novela francesa del XVIII que conforman el corpus de esta investigación ${ }^{7}$, encontramos ciertos ejemplares que pueden calificarse de ambiguos con respecto a la cuestión de quién habla en el prólogo y qué relación guarda el prologuista con respecto a la obra, esto es, qué régimen de verdad presentan sus declaraciones. Este tipo de ambigüedad afecta directamente al aspecto funcional del prólogo, su rasgo más definitorio y relevante. La cuestión de quién habla en el prólogo y qué relación guarda el prologuista con respecto a la obra, es un asunto capital y especialmente delicado en el prólogo de la novela del cronotopo que nos ocupa, y que sin duda traduce la existencia de un conflicto. Veamos algunos casos significativos.

En primer lugar, el efecto ambiguo se produce por una estratégica omisión de información por parte del prologuista: se trata de un tipo de ambigüedad que la tipología de Empson califica en sexto lugar y que define "cuando una declaración no dice nada, por tautología, contradicción o declaraciones sin importancia, de este modo el lector se ve obligado a inventar declaraciones propias y es probable que entren en conflicto entre sí" ${ }^{\prime \prime}$ (Empson, 1949: 207). Pues bien, como ejemplo de esta práctica, aparece el discurso prefacial de Margot la ravaudeuse (1748), de Fougeret de Monbron: "Voici enfin cette Margot la ravaudeuse, dont le général de la Pousse, sollicité par le corps des catins et de leurs infâmes suppôts, voulut faire un crime d'Etat à son auteur. Comme on ne l'accusait pas moins que d'avoir attaqué dans cet ouvrage la religion, le gouvernement et le souverain, il s'est déterminé à le mettre au jour, craignant que son silence ne déposât contre lui et qu'on le crût réellement coupable. Le public jugera qui a tort ou raison" (Monbron (1748), 1993: 677) ${ }^{9}$.

Este breve discurso prefacial que, por otra parte, carece de título que lo identifique como tal, el lector puede atribuirlo ya al editor, ya al redactor, ya al autor. Dada su función, me inclino a considerarlo autorial, en un uso en el que su autor prefiere esconderse en una tercera persona para dar más credibilidad a la función justificativa y de promoción hacia su obra, ambas poco lícitas si provienen del propio autor. Fougeret de Monbron ni asume ni niega la autoría: sencillamente se esconde y lleva

\footnotetext{
${ }^{7}$ En total, 651 prólogos de 464 novelas francesas del siglo XVIII, de 166 autores conocidos y 28 anónimos.

${ }^{8}$ Textualmente: "An ambiguity of the sixth type occurs when a statement says nothing, by tautology, by contradiction, or by irrelevant statements ; so that the reader is forced to invent statements of his own and they are liable to conflict with one another".

${ }^{9}$ Las referencias bibliográficas de prólogos del siglo XVIII presentan, tras el apellido del autor, la fecha de aparición del prólogo en cuestión, entre paréntesis y, cuando se trata de ediciones posteriores a la primera, se especifica en nota. La siguiente fecha que figura y el $\mathrm{n}^{\circ}$ de página se refiere a la fuente casi siempre moderna de la que proceden los prólogos.
} 
a cabo un prólogo autorial dejando ambigua la cuestión de quién lo locuciona. La falta de información, la ausencia de título, el distanciarse del autor como si el que hablase fuera otro, cumpliendo, sin embargo, una función claramente autorial, permiten considerarlo como un prólogo voluntariamente ambiguo por parte de quien lo emite, quien prefiere no identificarse, lo que le permite no asumirlo y dejar no resuelto el requisito mínimo de la información necesaria. Un caso similar aparece en el Préface de Restif de la Bretonne a Les Nuits de Paris ou le spectateur nocturne (1788):

Dans le tour de vingt années ; c'est-à-dire, depuis 1767, que l'Auteur est spectateur nocturne, il a observé pendant 1001 Nuits, ce qui se passe dans les rues de la Capitale [...] Il a donné à cet Ouvrage la forme animée du récit; parce qu'effectivement, il a rendu compte à une femme de tout ce qu'il voyait. On vous présente avec confiance ces Tableaux nocturnes, ô Concitoyens !, comme les plus curieux qui aient jamais existé : Ils instruiront, en étonnant. Vous y verrez non seulement des scènes extraordinaires, mais des morceaux philosophiques, inspirés par la vue des abus qui se commettent sous le voile ténébreux que la nuit leur prête; des histoires intéressantes, en un mot, tout ce qui peut exciter la curiosité (Restif de la Bretonne (1788), 1960: 2-4).

De nuevo se trata de un prólogo que, aparentemente, podría clasificarse bien como autógrafo de Restif, bien como alógrafo real y que, sin embargo, presenta unas funciones claramente autoriales referidas a la génesis de la obra y a su importancia en función de la instrucción que ofrece. Se trata de un testimonio en forma novelada ya que el autor pretende contarlo a una dama, lo cual implica también un choix, ya que aparece su elección del lector, la mujer. Pero, como en el caso anterior, este préface no se atribuye ni al autor ni al editor, ya que ni el título ni los deícticos del discurso apuntan a ninguno en concreto, y aunque la cuestión se presenta pretendidamente ambigua, no obstante las funciones del prólogo nos indican que no se trata de un prólogo alógrafo auténtico, como podría serlo, por ejemplo, el de un editor distinto de la persona del autor, algo que en Restif complica la cuestión, ya que sabemos que solía editar sus propias obras, lo cual le permite jugar en ocasiones con el lector. En este caso concreto, el autor emite su discurso prefacial camuflado en una voz ambigua ya que, aunque quien habla es el autor, lo hace desde un distanciamiento estratégico cuando se refiere a él mismo o a su obra desde la tercera persona, es decir, pretendiéndose otro, pero sin aclararlo tampoco. En último término, quien conoce el dato biográfico de que este autor suele editar él mismo sus obras puede sentirse cómplice de su juego, pero quien lo desconozca puede dar más credibilidad a las declaraciones prefaciales. Restif, en su doble calidad de autor y editor, es un buen ejemplo de prologuista voluntariamente ambiguo, haciendo de ello un alarde lúdico y provocando al lector en numerosas ocasiones. Como ejemplo suplementario y muy revelador al respecto, tenemos el que aparece en La Paysanne pervertie (1784), en su prólogo L'éditeur au lecteur, que no puede ser más revelador: "J'offre avec confiance cet ouvrage au public ; que j'en sois l'auteur, ou que j'aie mis seulement en ordre les lettres qui le composent, il n'en est pas moins vrai, [...]" (Restif De La Bretonne (1784), 1972: 37).

Este prologuista que habla en primera persona se identifica por la denominación del título como editor, aunque deje ambigua la cuestión de la autoría de la obra. El 
editor puede que sea el autor, o bien la persona que simplemente ordena las cartas que componen esta historia. Ambas cosas son posibles pero, evidentemente, no son compatibles. Pero además, en el siguiente discurso prefacial, denominado Préface de l'éditeur, añade: "Je reprends ici un titre qui m'appartient" y, de nuevo, lo único que reconoce este locutor es el prólogo, sin asumir la obra, a la que sencillamente presenta como una continuación de Le paysan perverti. Tras el prólogo ambiguo anterior en éste vuelve a sugerir que tan sólo es su editor, pero tampoco niega que sea su autor, ya que lo sugiere de modo ambiguo y tras haber emitido un discurso contradictorio. El orden de aparición de las distintas declaraciones autoriales, en suma, es el siguiente:

Yo no soy el autor, sino un mero adaptador (subtítulo).

Qué importa que sea autor o editor, nada de ello es mentira ( $L$ 'Éditeur au lecteur).

Yo soy editor, éstas son las cartas de Ursula, hermana del Paysan perverti, y puede considerarse continuación de dicha obra (Préface du rédacteur).

Se trata de mostrar el rostro y la voz, pero camuflando al mismo tiempo la pluma o la autoría, ya por aportar un suplemento de verosimilitud a las obras, con un efecto de realismo, ya por escapar a los temidos reproches y represalias de crítica y censura, ya por ambas cosas. J. Herman, sustentándose en los trabajos de E. Zawisza (1977) al respecto, subraya que es, sobre todo en la primera mitad del siglo, esta segunda razón el principal motivo de buena parte de los prólogos en los que el autor se camufla en editor:

$\mathrm{Au}$ début du siècle surtout, la préface apparaît comme une injonction dictée par la tradition et l'usage devant lesquels l'auteur déclare s'incliner bon gré mal gré. La seule nécessité intrinsèque de la préface réside dans la défense du texte publié. Cette défense, face à une critique hostile et à la censure, s'effectue par des techniques narratives de camouflage. En se présentant comme éditeur, l'auteur décline la responsabilité pour les défauts de l'œuvre et fait valoir ses opinions en les mettant sur le compte d'un autre (Herman et al., 2008: 46).

para, más adelante, matizar:

Dans un climat où les interdits implicites, qui agissent de manière diffuse dans le champ culturel classique, poussent l'auteur à ne se montrer qu'après que le public l'a autorisé à paraître, la préface est un espace pragmatique où l'auteur, en s'effaçant, s'interdit la posture en tête de l'œuvre, se ménageant dans le désaveu une marge de négociation avec le public, qui le reconnaîtra ou ne le reconnaîtra pas, qui lui attribuera l'œuvre ou l'attribuera à un autre. En attendant, l'auteur se protège par l'anonymat ou par une fiction préfacielle où il dénie la paternité de l'œuvre en se donnant pour l'éditeur d'un texte dont il n'est pas responsable (Herman et al., 2008 : 97-98).

Otro tipo de prólogos ambiguos son aquellos en los que, en el mismo enunciado, un locutor comienza declarándose como un pseudo-editor con ciertas responsabilidades hacia la obra, para, finalmente, dejar alguna pista que permita considerarle como autor, si bien ni niega ni asume la autoría. Un prólogo representativo de esta categoría pertenece a Rustaing de Saint-Jory en Histoires galantes, nouvelles et 
véritables par M. le Chevalier de R. C. D. S. (1720). El título de la obra la atribuye a un Chevalier de R. C. D. S. Sin embargo, en el Préface, el "Je" locutor del prólogo, que se identifica con el autor real, asume la escritura de la misma como mero testigo, para más adelante proponer unos indicios que le señalan claramente como su autor sin que, sin embargo, asuma la obra: "Il y a longtemps qu'il m'était venu dans la pensée de faire un recueil des plus mémorables événements, dont il m'arriverait d'être témoin [...]". Sin embargo, al final del prólogo, su actitud y su responsabilidad hacia la obra se plantean de modo distinto: "Pour ce qui regarde les autres, il m'importe peu de quel œil ils verront mon ouvrage; ce n'est ni pour leur plaire, ni pour les chagriner que j'écris, c'est pour divertir les honnêtes gens, et moimême avec eux ; mais principalement le beau sexe [...]" (Rustaing De Saint-Jory (1720), $2002: 1275-1276)$.

De nuevo, las funciones claramente autoriales que este prólogo desarrolla conducirían a considerarlo como autorial real (autógrafo), a pesar de que el autor prefiera esconderse (cripto-autorial). En último término, la suma del subtítulo, en el que atribuye la obra a otro, las declaraciones iniciales que le presentan como un pseudo-redactor testigo de los hechos, y los indicadores posteriores por los que ya asume su obra y su escritura, permiten concluir que se trata de un prólogo pretendidamente ambiguo en grado mínimo que, de modo gradual y oscilante, se desliza, partiendo de una actitud de falsa alografia, hacia otra que le permita asumir su obra.

Un ejemplo con un grado de ambigüedad más importante viene dado por el discurso prefacial de Voisenon en el incipit de su Histoire de la Félicité (1751). El autor, tras una breve disertación acerca de la felicidad, añade: “[...] c'est ce que je vais prouver par l'histoire d'un père et d'une mère, qui, revenus de leurs erreurs, en firent le récit à leurs enfants, [...]" (Voisenon (1751), 1993 : 535-36). Tras referirnos la historia de la pareja y de cómo consideran que su ejemplo puede ser instructivo para sus hijos, este prologuista deja el relato y la historia como responsabilidad de uno de sus personajes, Thémidore: "Voici le récit de Thémidore à son fils". Con lo cual, parece que Voisenon lleva a cabo una atribución ficcional del relato de la historia a Thémidore pero, si nos atenemos a sus declaraciones iniciales del prólogo, no nos saca de dudas acerca de si la obra pertenece a Thémidore o a él mismo, ya que lo único que sabemos es que Voisenon cree que se trata de un relato instructivo, pero no aclara la cuestión de si la obra es invención suya y la pone en boca de su personaje, el cual, además, no queda claro que sea real o ficcional, con lo que Voisenon, se convertiría en mero redactor o testigo de una historia ajena que llega hasta él. De nuevo, se trata de un prólogo ambiguo por una omisión estratégica de cierta información, por lo que es difícil considerar este prólogo como alógrafo real o autorial (autógrafo) ya que, aunque no asume la obra, tampoco niega su paternidad, y es que un mismo enunciado nos sugiere dos posibilidades distintas y contradictorias. Cosa bien distinta es que el autor consiga engañarnos, ya que lo importante de estos casos es que su discurso resulte ambiguo y difícil de clasificar, lo cual, por otra parte, permite entenderlo dentro de uno de los modelos textuales propuestos por Velázquez: el referente a los usos evasivos. 
Por otra parte, una vez más, el recurso de la ambigüedad resulta un modo muy eficaz de intentar escapar a cualquier reproche de escribir una invención, y a todos los pecados que conlleva la escritura de una novela en la época. El conflicto ficción/realidad explica la actitud oscilante y ambigua de este prologuista-tipo. Algo muy frecuente, con distintos grados de ambigüedad o contradicción, como muestra el prólogo de E. Salverte a Un pot sans couvercle et sans rien dedans, ou Les mystères du souterrain de la rue de la Lune (1799). Desde el propio subtítulo nos sumerge en una pura contradicción en lo referente a su autoría, ya que tras indicar: Histoire merveilleuse et véritable, traduite du français en langue vulgaire par Louis Randol, añade: "Après ces aveux dépouillés d'amour-propre, souffrez que je rende justice à ma production et à moi. Remarquez d'abord cette finesse de m'intituler traducteur, et no pas auteur, tandis que je suis l'un et l'autre". Aunque, en este caso, el autor nos informa del motivo del enunciado ambiguo: "Mais je sais que le plus mauvais roman ne trouverait pas un lecteur parmi vous, si vous ne lisiez au titre, en majuscules capitales, TRADUIT, etc., C'est là votre boussole, j'ai pensé dire votre guidâmes". Y, más adelante, aún añadirá: "l’histoire que j'écris [...]" (Salverte (1799), 2003: 391-393)

Lo cierto es que, como ya he señalado, el dilema ficción/realidad determina la actitud oscilante o ambigua de estos prologuistas. Lo cual -tal y como ellos mismos manifiestan- provoca incertidumbre en el lector pero, por su condición de discurso ambiguo, resulta muy excitante y aumenta el placer de la lectura. Nadie explica mejor la funcionalidad de tal estrategia como Marivaux en su prólogo a Le Télémaque travesti (1736), en el que señala: “[...] quelque sérieux ne pourra s'empêcher de demander si mon histoire est vraie. Je ne répondrai ni oui, ni non; l'incertitude où je laisse le lecteur ne contribuera peut-être pas peu à soutenir le plaisir de la lecture..."” (Marivaux (1736), 1972: 722).

Esta misma razón lleva a Rousseau a practicar la ambigüedad de sus prólogos. Cuestión que se constata de modo diferente a los ejemplos anteriores, ya que existen prólogos ambiguos en sí mismos, y prólogos que, siendo fácilmente reconocibles o clasificables como pertenecientes a una u otra tipología, funcionan sin embargo como elementos o sumandos de un plan u operación más amplio, previamente maquinado por el autor, cuyo resultado o consideración total del paratexto producen como resultado un enunciado conjunto ambiguo. Por ejemplo, el Préface de La Nouvelle Héloïse es claramente un prólogo ambiguo al que le sigue un prólogo dialogado que tampoco nos saca de dudas, sino todo lo contrario, y que además pretende convencer de los beneficios de la propia duda o ambigüedad. Algo que también practican Laclos o Sénac de Meilhan, y que evidencia que, aunque un prólogo concreto sea clasificable en una tipología concreta, la suma de todos los discursos prefaciales que forman el paratexto total de la obra en que aparece, y por tanto la consideración del conjunto del enunciado, puede ofrecernos un discurso finalmente ambiguo.

A este tipo de ambigüedad responde el análisis del conjunto paratextual de $L a$ Nouvelle Héloïse de Rousseau, esto es: de su Préface y de sus apéndices: Avertissement y Préface de Julie ou Entretien sur les Romans: 
$1^{\circ}$ - El Préface, un prólogo autorial denegativo, dice por boca de Rousseau: "Quoique je ne porte ici que le titre d'Éditeur, j'ai travaillé moi-même à ce livre, et je ne m'en cache pas". Con lo cual, se define como un pseudo-editor con cierto grado de responsabilidad hacia la obra que presenta. Algo que, sin embargo, seguidamente prefiere dejar ambiguo: "Ai-je fait le tout, et la correspondance entière est-elle une fiction? Gens du monde, que vous importe ? C'est sûrement une fiction pour vous" (Rousseau (1761), 1967: 3). Así, el prologuista Rousseau declara que su responsabilidad puede ser mayor que la de un mero editor que haya contribuido a la obra con alguna aportación personal, y que incluso toda la correspondencia podría ser obra suya. Se trata, en consecuencia, de un prólogo que, en su comienzo, oscila entre denegar la obra y asumir cierta responsabilidad mínima, para finalmente dejar la cuestión no resuelta, recurriendo a la ambigüedad.

$2^{\circ}$ - Un breve Avertissement autorial original informa que, seguidamente, incluye un Préface que -aunque debía preceder a la obra, como es lo usual- lo sitúa tras la misma por su gran extensión, además de indicarnos que se trata de un entretien supposé o simulado, es decir, inventado o ficcionalizado.

$3^{\circ}$ - En el Préface de Julie ou Entretien sur les Romans, se escenifica la siguiente argumentación ambigua a modo de diálogo:

N.: Quand je vous demande si vous êtes l'auteur de ces Lettres, pourquoi éludez-vous ma question?

R.: Pour cela même que je ne veux pas dire un mensonge.

N.: Mais, vous refusez aussi de dire la vérité ?

R.: C'est encore lui rendre honneur que de la déclarer qu'on veut la taire : Vous auriez meilleur marché d'un homme qui voudrait mentir. D'ailleurs, les gens de goût se trompent-ils sur la plume des Auteurs? Comment osez-vous faire une question que c'est à vous de résoudre? (Rousseau (1761), 1967: 584).

y, nuevamente, este discurso prefacial se declara ambiguo frente a la ficcionalidad o autenticidad de las cartas que conforman esta obra, así como en lo concerniente a la cuestión de asumir o no la obra por parte de su autor.

Rousseau se muestra impenetrable, enigmático y ambiguo -a pesar de la insistencia de su interlocutor-, pero deja claro que se trata de una cuestión que el lector debe resolver por sí mismo. El lector sutil debería entender que Rousseau busca neutralizar ese clásico reproche, fundado en un horizonte de expectativas propio de la época y basado en que "si ces Lettres sont des Portraits, ils n'intéressent point ; si ce sont des Tableaux, ils imitent mal..." Sin embargo, si no se sabe con certeza qué son realmente, esta crítica se desvanece y además esa oscilación entre dos posturas, esa duda que sufre el lector y que viene provocada por un mensaje ambiguo, estimulan enormemente su curiosidad y su intriga. El diálogo continúa: 
N.: Je ne conclus pas ; je doute, et je ne saurais vous dire combien ce doute m'a tourmenté durant la lecture de ces lettres. Certainement, si tout cela n'est que fiction, vous avez fait un mauvais livre ; mais dites que ces deux femmes ont existé, et je relis ce Recueil tous les ans jusqu'à la fin de ma vie (Rousseau (1761) 1967 : 585)

para añadir, finalmente: "Tout le monde aura la même curiosité que moi".

Pues bien, ese es el efecto que Rousseau pretende provocar en su interlocutor, en ese trasunto del lector implícito con el que espera encontrarse y en el que, mediante esta estrategia, intenta influir. Como en todos los casos, la negación u oscilación entre aceptar o negar la paternidad de una obra responde a la búsqueda del efecto de realismo, de autenticidad de las historias narradas, por lo que, tras su ambigua declaración acerca de si es el editor o el autor -o ambas cosas o, ¿quizás? ningunade las cartas que presenta, subraya:

Quant à la vérité des faits, je déclare qu'ayant été plusieurs fois dans le pays des deux amants, je n'y ai jamais ouï parler du... [...] J'avertis encore que la topographie est grossièrement altérée en plusieurs endroits ; soit pour mieux donner le change au lecteur, soit qu'en effet l'auteur n'en sut pas davantage. Voilà tout ce que je puis dire. Que chacun pense comme il lui plaira (Rousseau (1761), 1967: 3)

¿No son éstos, precisamente los términos, mutatis mutandis, de Empson?

Otro prólogo que oscila entre la actitud de denegar y la de asumir la paternidad de la obra es el de Les liaisons dangereuses, de Laclos. La modalización ambigua del discurso prefacial aparece desde el primer momento:

Nous croyons devoir prévenir le Public que, malgré le titre de cet Ouvrage et ce qu'en dit le Rédacteur dans sa Préface, nous ne garantissons pas l'authenticité de ce Recueil, et que nous avons même de fortes raisons de penser que ce n'est qu'un Roman... (Laclos (1782), 1979: 3).

Estas declaraciones del pretendido Editor contradicen las contenidas en el subtítulo que aparece en la portada y que presenta a la obra como la recopilación de un conjunto de cartas encontradas en una sociedad y publicadas con un fin moralizante. El autor se presenta como mero editor de las mismas y, por ello, el prólogo del editor debe ser entendido como autorial original pero con una actitud inicialmente denegativa que oscila, sin embargo, en cuanto a su grado de responsabilidad, y en el que se pone en duda que se trate de una serie de cartas reales. Más bien se diría que se trata de una novela, con lo cual el autor, que negaba la paternidad de la obra, pasaría a asumirla, si bien de un modo confuso y estratégicamente ambiguo. Lo contradictorio de sus declaraciones, en función del paratexto de la obra, se produce en el sentido y orden siguientes:

$1^{\mathrm{o}}$.- Se trata de una serie de cartas encontradas y publicadas por Laclos (subtítulo): Lettres recueillies... et publiées pour l'instruction de quelques autres (Laclos (1782), 1979: 1).

$2^{\circ}$.- Se pone en duda la autenticidad de las cartas, y el editor se inclina a pensar que se trata de una novela (Avertissement de l'Éditeur): “...malgré le titre de cet 
ouvrage... nous ne garantissons pas l'authenticité de ce Recueil, et nous avons même de fortes raisons de penser que ce n'est qu'un Roman" (Laclos (1782), $1979: 3)$

$3^{\circ}$.- El redactor considera que se trata, más que de una obra de ficción o de una novela, de una recopilación de cartas auténticas (Préface du Rédacteur): "Cet ouvrage, ou plutôt ce Recueil...” (Laclos (1782), 1979: 5).

Pues bien, algo similar encontramos en los prólogos de L'Émigré, de Sénac de Meilhan. De nuevo se trata de un juego entre realidad y ficción característico del género epistolar, y que -como en los casos anteriores- también se desprende de la estratégica suma del conjunto del paratexto. En principio, puede entenderse que se trata de una serie de cartas pretendidamente auténticas y validadas por un fondo histórico. Sénac nos dice en su incipit: "On ne doit pas perdre de vue que les lettres qui composent ce recueil ont été écrites en 1793. La plupart des tableaux et des sentiments qu'elles renferment sont relatifs à cette époque affreuse et unique dans l'histoire" (Sénac de Meilhan (1797), 2004: 31). Pero también, por el contrario, puede tratarse de una mera invención o de una historia auténtica. Sin embargo, en el Préface de la obra, añade:

L'ouvrage qu'on présente au public est-il un roman, est-il une histoire ? Cette question est facile à résoudre. On ne peut appeler roman un ouvrage qui renferme des récits exacts de faits avérés. [...] Le nom du marquis de Saint Alban est inconnu, [...] je n'en sais rien ; mais les événements qu'il raconte sont vrais, [...] Tout est vraisemblable, et tout est romanesque dans la révolution de la France (Sénac de Meilhan (1797), 2004: 32).

En su incipit, el autor o pretendido editor se propone autentificar la correspondencia que se presenta como una producción bien ubicada en un contexto histórico concreto, dotándola así de credibilidad. Sin embargo, en el Préface siguiente, contradice lo anterior y establece la duda acerca de si dicha correspondencia es real o ficticia, oscilando entre ambas posibilidades sin resolverlas, por lo que el autor ni asume ni niega su autoría, ya que si se tratase de una correspondencia real el autor se convertiría en un mero pseudo-editor, pero si las cartas son una ficción debe asumir tanto la ficcionalidad como la autoría de dicha obra. Y es que, aunque al final del segundo de los discursos prefaciales añada: “Je n'en dirais pas davantage sur cet ouvrage ; s'il intéresse, je n'aurai pas eu tort de le publier [...]", en realidad nos encontramos ante dos prólogos cuya suma produce un enunciado paratextual ambiguo, voluntaria y estratégicamente ambiguo.

Dentro de los siete tipos de ambigüedad que establece Empson, estos tres casos que acabo de analizar desarrollan el descrito en cuarto lugar, y que viene dado por un texto contradictorio en el que dos o más significados no están de acuerdo, pero se combinan de tal modo que manifiestan -ya sea de modo claro o implícitamenteque el conflicto del autor le hace comunicar de manera sesgada. Si bien, considerando los prólogos de manera independiente, también encontramos su séptimo tipo, que puede resumirse como un enunciado con términos opuestas que vienen a expo- 
ner la clave del conflicto. Este aspecto se manifiesta en el prólogo que a modo de diálogo presenta La Nouvelle Héloïse: "N.- Cette correspondance est-elle réelle, ou si c'est une fiction? [...] R.- [...] D'ailleurs, vous jugez ce que vous avez lu comme un roman. Ce n'en est point un ; vous l'avez dit vous-même. C'est un recueil de lettres..." (Rousseau (1761), 1967: 571). O, también, en el Préface de L'Émigré: "L'ouvrage qu'on présente au public est-il un roman, est-il une histoire ?" (Sénac de Meilhan (1797), 2004: 32).

Finalmente, encontramos el tipo sexto de la tipología de la ambigüedad de Empson, que podría resumirse como aquella que realmente no dice nada, por tautología, contradicción o en términos irrelevantes; $y$ en la que los lectores se ven obligados a inventarse una interpretación propia -por ello, de la que ellos mismos son los únicos responsables-, y que es posible que entre en conflicto con la idea del autor. Pero, ¿cuál es la idea del autor? Seguimos con Rousseau : "Quoique je ne porte ici que le titre d'éditeur, j'ai travaillé moi-même à ce livre, et je ne m'en cache pas. Ai-je fait le tout, et la correspondance entière est-elle une fiction ?" Pregunta a la que el autor ni responde, ni confirma, ni niega, sino que se limita a sugerir cualquiera de las posibilidades que puede contestar el lector: "C'est sûrement une fiction pour vous". A lo que finalmente añade: "Quant á la vérité des faits [...] que chacun pense comme il lui plaira". (Rousseau (1761), 1967: 3).

En las tres obras comentadas, el lector se ve abocado a una libre interpretación, dentro de la multiplicidad de planos en los que el contenido podría interpretarse. Esta enunciación contradictoria que oscila entre las actitudes de negar, asumir y volver a negar la paternidad de una obra, es una magistral estrategia de los autores que, gracias a estos distintos prólogos ficcionales ambiguos, consiguen transmitir un discurso que admite y provoca diversas interpretaciones simultáneas. Se trata de un comportamiento enunciativo que vela o encubre las verdaderas intenciones autoriales, ya que escamotea cualquier posible jerarquización de las interpretaciones o cualquier criterio que aporte un máximo de fiabilidad. No en vano la ambigüedad del autor se extiende por ejemplo -en el caso de Laclos- también a su declaración de intenciones, a la utilidad de la obra y a la elección del lector, todas ellas funciones clave del prólogo original (el autorial en su edición original y asumido por el autor), aunque tal y como hemos visto se trate ya de prólogos autoriales denegativos, en los casos del comentario del título y del Préface du rédacteur y de alógrafo ficticio en el del Avertissement de l'éditeur.

En los tres casos referidos se produce una estrategia similar que, partiendo de la obra de La Nouvelle Héloïse de Rousseau, intertextan las dos posteriores: Les Liaisons dangereuses, en 1782, y L'Émigré, en 1797. En estas tres obras, aunque cada prólogo se clasifique como perteneciente a varias subtipologías del prólogo ficcional, siendo el Préface de Julie ou Entretien sur les romans susceptible de considerarse una forma mixta de autorial original y ficcionalizado, por la puesta en escena de una conversación ficticia aunque posible -entre el autor real y un críticodeben ser tipificados como ficcionales y ambiguos por el juego paratextual que establecen, cuya consideración de conjunto produce un enunciado estratégicamente ambiguo. Pero el caso de Prévost con su Cleveland no puede ser más revelador. En 
el momento de su aparición, en el Préface del T. I, indica: "L'histoire de M. Cleveland m'est venue de bonne source. Je la tiens de son fils, qui porte le même nom, et qui vit actuellement à Londres dans une heureuse vieillesse. [...] Il avait lu mes Mémoires et ce fut la plus forte raison qui le porta à me parler de ceux de son père". (Prévost (1731), 1977: 9). Habrá que esperar hasta la aparición del T. IV, en 1738, y, sobre todo, a su confesión autorial encabezando el T. VI (Prévost (1731), 1977: 355-57), para que veamos al autor reivindicar la autoría de la obra. Es evidente que la enunciación ambigua - desde el punto de vista de la oscilación entre negar y asumir la paternidad de la obra- tiene sus ventajas para el autor. Por lo que le respecta, con un mismo enunciado responde al esperado reproche de invraisemblance y de presentar una invención o novela, neutralizando así las dudas o las incertidumbres del crítico $-\mathrm{y}$, por consiguiente, su actitud censora-, mientras que por parte del lector aumenta el placer de la lectura. La actitud igualmente velada y confusa con respecto a la declaración de intenciones o elección del lector busca, además de simular que se trata de un prólogo serio que, en este caso, se propondría alertar a las jóvenes ante la corrupción masculina, satisfacer también al mayor número de lectores e interesarles.

Toda pretensión de no presentar o escribir una novela suele venir argumentada por un requisito previo de alografia falsa, que por supuesto se pretende auténtica, y es que algo que posea una existencia anterior e independiente del autor o prologuista que la presenta, aparece como un relato dotado de cierta historia, con lo cual se impregna de cierto efecto de autenticidad. Al igual que un relato biográfico dota a los personajes ficticios de un halo de realismo, del mismo modo las obras que responden al topos de los manuscritos encontrados y la historia de cómo llegan a manos del pretendido pseudo-editor son también en cierto modo una biografía o historia de la vida y aventuras de las propias obras, que marcan su carácter ficcional con un sello de autenticidad. Así, algunos prólogos pueden ser considerados autoriales originales o alógrafos auténticos, ya que el autor parece no definirse realmente por ninguna de las dos actitudes y vacilar entre ambas a propósito, mientras que en otras se declara pretendidamente ambiguo, fluctuando entre un autorial o un alógrafo ficticio, pudiendo ser ambas cosas al mismo tiempo, ya que, cuando un autor asume claramente la obra, es autorial original y, sin embargo, cuando ni la asume ni la niega y las huellas textuales resultan insuficientes para determinar si apunta al autor real o a un editor distinto del autor, resulta ambiguo. La estrategia de la ambigüedad de nuestros prólogos supone, así, un sutil modo de esconderse y aparecer, de afirmar y negar, de justificarse e intrigar, de ofrecer con un mismo enunciado un doble o múltiple significado mediante el que "chacun pense comme il lui plaira" (Rousseau) o que, tal y como expresaba Marivaux en Le Télémaque travesti, contribuya a mantener la incertidumbre del lector y a sostener el placer de la lectura en la obra.

Si a todo ello añadimos la ya mencionada función preventiva y neutralizadora, debemos concluir que esta estrategia de la ambigüedad es uno de los modos más económicos, sutiles y eficaces de conseguir los propósitos o funciones que caracterizan al prólogo autorial en general y al de la novela francesa del siglo XVIII, en 
concreto. La economía enunciativa, esto es, decir más con menos, facilitando un abanico abierto de interpretaciones, así como la eficacia que debe caracterizar a un prólogo, constituyen otra de las ventajas del discurso ambiguo. Por otro lado, velar, esconder o definir de modo engañoso unas intenciones autoriales en un momento en que novela y novelista resultan genéricamente sospechosos -en sus intenciones, en sus formas-, al tiempo que deben satisfacer las demandas de unos nuevos lectores cada vez más influyentes, aparece como un recurso especialmente oportuno e indicado, sobre todo vista la relevancia que adquieren los prefacios de la novela de esta época, en los que buena parte de las estrategias autoriales se proponen hacer pasar las obras por lo que no son.

\section{B. La ambigüedad en la declaración de intenciones}

La estrategia de la ambigüedad aparece muy especialmente en la declaración autorial de intenciones que, según Genette, resulta ser la función más importante del prólogo autorial original, ya que consiste en la interpretación del texto por parte del autor. En el prólogo de la novela francesa del XVIII abundan los casos en los que dichas declaraciones de intenciones son ambiguas, contradictorias o poco sinceras. Habitualmente, es muy fácil encontrarlas en los prólogos de novelas filosóficas, tal y como califica este siglo a aquellas que ponen en cuestión los principios de la moral, la religión, la Iglesia, la Monarquía, el Parlamento, etc., y puede decirse que se trata de aquellas declaraciones autoriales que, por una función preventiva y justificativa hacia la crítica o las represalias temidas por el contenido subversivo de las obras, presentan en el prólogo unas declaraciones ambiguas, que pretenden encubrir la crítica que los textos llevan a cabo hacia la bienséance.

Un buen ejemplo de esta práctica ambigua de declaración de intenciones lo encontramos en los prólogos de obras libertinas ${ }^{10}$. Así, Sade, en su prólogo a Eugénie

\footnotetext{
${ }^{10}$ Lo cual nada tiene de extraño si nos atenemos a las características del cuarto modelo de escritura, referido al erotismo, propuesto por J. I. Velázquez: "Es siempre el triunfo del discours de la connotación sobre el de la denotación (que es, por otra parte, la expresión de la pornografía, que nada tiene que ver con el erotismo, dicho sea de paso)... [...] Es la escritura de lo sugerido y lo implícito, siendo ella misma estrategia de seducción, la de un lector cuyas capacidades de representación son también manipuladas por los artificios del autor. Pues éste se aprovecha del estado de attente del lector, cuyo deseo le hace interpretar a su manera las ambigüedades que el autor le suministra. Siendo la ambigüedad, entre otras, el lenguaje del deseo, ese deseo se manifiesta en el texto por la morosidad de su cadencia o por la importancia concedida a la descripción. Pero la ambigüedad es también la manifestación del Otro, sexualizado en esta ocasión, y para dominarla y devolverle al lector su propia confianza, se busca resolverla a través de un tópico, a saber, la norma de que la posesión excluye el erotismo, pues no hay Otro posible, una vez resuelto en la mismidad. Lo cual quiere decir que no hay erotismo más que en el deseo, es decir, en el trayecto, es decir en las manifestaciones de ambigüedad textual..." (Velázquez, 2005a: 735-736).
} 
de Franval (1800), declara sus pretendidas intenciones hacia su obra del modo siguiente:

Instruire l'homme et corriger ses mœurs, tel est le seul motif que nous nous proposons dans cette anecdote. Que l'on se pénètre, en le lisant, de la grandeur du péril, toujours sur les pas de ceux qui se permettent tout pour satisfaire leurs désirs! Puissent-ils se convaincre que la bonne éducation, les richesses, les talents, les dons de la nature, ne sont susceptibles que d'égarer, quand la retenue, la bonne conduite, la sagesse, la modestie ne les étayent, ou ne les font valoir: Voilà les vérités que nous allons mettre en action (Sade (1788), 1967: 367).

El contenido ambiguo de la declaración de intenciones surge cuando el lector dispone de un conjunto de informaciones que implica una doble lectura interpretativa, ya que la actualización implícita de su enunciado sugiere que la instrucción del hombre pasa por subvertir las costumbres morales establecidas en función de los proyectos liberadores del deseo del autor. El enunciado reseñado, en sí mismo, se propone transmitir una función preventiva y neutralizadora ante la represalia esperada en función de la ideología subversiva que transmite la obra. En este marco, cobran todo su sentido los términos en que se expresa M. Kozul: "La Préface est bien un discours séducteur qui s'affirme en dénonçant les exigences posées par le discours poétique ou orthodoxe prescriptif, tout en feignant de s'y soumettre" (Herman et al., 2008: 207).

Pues bien, mucho más ambigua aún se muestra su declaración de intenciones en los prólogos de Justine ou les malheurs de la vertu (1791). En el Avis de l'éditeur, refiriéndose a la actividad y posición del novelista en cuanto a la representación o la pintura de los vicios y costumbres inmorales, manifiesta:

N'a-t-il pas le droit de les peindre tous pour les faire détester aux hommes ? Malheur à ceux que les tableaux de Justine pourraient corrompre! Mais qu'on ne nous en accuse pas ; quelque voie que nous eussions prise, ils n'en seraient pas devenus meilleurs : il est une sorte de gens pour qui la vertu même est un poison (Sade, (1788), 1995: 127).

De manera que, en un primer momento, adopta el argumento más practicado por los prólogos de textos libertinos, que de modo recurrente y cínico a veces, pretenden neutralizar y prevenir la crítica de los cuadros de vicios e inmoralidades que presentan, bajo el argumento de que se trata de ejemplos a no imitar y, paradójicamente, de indiscutible valor moralizante. Pero, poco después, ya emite otro mensaje contradictorio que, a pesar de su modalización encubierta justificativa, sugiere de modo implícito que existe otro tipo de moral para la cual la virtud es un veneno.

Para reforzar este implícito mensaje autorial, aparece un segundo prólogo a modo de dedicatoria, "À ma bonne amie", pretendidamente dedicado a Constance, con todas las connotaciones de virtud y resignación femeninas que implica dicho nombre, con esa actitud o valor moral que Sade se propone subvertir con estos objetivos explícitos: "connaître la douceur des larmes qu'arrache la vertu malheureuse... [...] détestant les sophismes du libertinage et de l'irreligion, les combatant sans cesse..." (Sade, (1788), 1995: 129). Su declaración de intenciones parece elocuente: "Après avoir lu Justine, en un mot diras-tu : "Ô combien ces tableaux du crime me rendent 
fière d'aimer la vertu"! Comme elle est sublime dans les larmes! Comme les malheurs l'embellissent! Ô Constance ! que ces mots t'échappent, et mes travaux sont couronnés" (Sade, (1788), 1995: 130).

Los deseos manifiestos de Sade con respecto a su obra, puestos en relación con las declaraciones anteriores, acaban produciendo un efecto de confusión que pretende satisfacer a varios lectores con un único enunciado: algo que la estrategia de la ambigüedad le permite. Claro que con una matización posterior, ya que el enunciado vuelve a dar un giro importante que entra en contradicción con las preventivas declaraciones anteriores y sugiere otras bien distintas, como puede comprobarse: "Le dessein de ce roman est nouveau sans doute ; [...] mais offrir partout le vice triomphant et la vertu victime de ses sacrifices, montrer une infortunée errante de malheurs en malheurs..." (Sade, (1788), 1995: 129). Estas son las intenciones auténticas que el autor pretende con su obra, pero prefiere manifestarlo de modo encubierto y, además de verse precedidas por otras contradictorias y pretendidamente reales, cuando estas últimas, las auténticas, se producen, lo hacen subordinadas a los valores de originalidad e importancia de la obra, que indiscutiblemente existen, pero con las que trata de camuflar la auténtica declaración de intenciones. De manera que, al final, tenemos dos bien distintas, y será responsabilidad de cada lector actualizar su lectura en la dirección que su autor ha pretendido. La primera de ellas ejerce una función neutralizadora, la segunda subversiva.

Esta ambigüedad en la declaración de intenciones aparece en muchos de los epílogos de obras libertinas. Si bien ya no pretenden proponer una línea de lectura como en los prólogos, sino corregir una lectura o interpretación del cuadro del mal ejemplo, en el sentido del contenido moral en el que su autor supuestamente pretende haberlo generado. En ellos encontramos modelos argumentativos de un contenido moral en acción, cuyo poder persuasivo se ve privilegiado por la fuerza de convicción que el discurso filosófico confiere al cuadro, a la pintura o a la representación, siempre dentro del espíritu pedagógico que caracteriza a este cronotopo del Siglo de las Luces. Buen ejemplo de ello son los discursos autoriales de Restif de la Bretonne en La jolie solliciteuse (1785), o el de Sade en su Postface a Les crimes del amour. El primero no puede ser más elocuente:

Quel est le but principal de cette Nouvelle? Hommes en place, je vous conte bonnement ce que j'ai appris de vos pareils, pour vous préserver des pièges qui vous sont tendus: Il est cruel de manquer à son devoir, pour une jolie friponne, dont on est la dupe ! Et c'est ce qui arrive le plus souvent. Quant à Elvirette, elle était charmante; sa beauté fut le seul piège qu'elle tendit: mais combien en est-il, qui réussissent par la duplicité, la fourberie ! Qui, feignant une trompeuse innocence, substituent au remords de l'avoir détruite, la honte de s'être apparié avec une fille publique, le rebut des libertins les plus crapuleux (Restif de La Bretonne (1785), 2002 : 1060).

Sade, a su vez, manifesta: Si les pinceaux dont je me suis servi pour te peindre le crime, t'affligent et te font frémir, ton amendement n'est pas loin et $\mathrm{j}$ 'ai produit pour toi l'effet que je voulais. Sabemos bien que ambas declaraciones autoriales de intenciones son tan ambiguas como falsas, pero resultan ser las premisas necesarias para el desarrollo de la función correctiva de la interpretación de la obra que carac- 
teriza al epílogo. De nuevo, la estrategia de la ambigüedad transmite un mensaje doble con un único enunciado, ya que trata de influir tanto en la interpretación o lectura del crítico o del censor, ante los que se pretende hacer pasar la obra por lo que no es, una vez que ya la han leído, como al lector ideal, al que se le comunica de un modo más sutil e implícito el auténtico sentido de la misma, esto es, el modo en el que debe ser actualizada, aquél que más se acerca al sentido o estructura profunda en el que su autor la ha generado. Y también resultan tan falsas como ambiguas las declaraciones de intenciones del prólogo autorial denegativo del redactor de Les Liaisons dangereuses de Laclos, cuando dice: « ...il me semble au moins que c'est rendre un service aux mœurs, que de dévoiler les moyens qu'emploient ceux qui en ont de mauvaises pour corrompre ceux qui en ont de bonnes, et je crois que ces lettres peuvent concourir efficacement à ce but »(Laclos (1782), 1979: 7).

Finalmente, como un interesante ejemplo de ambigüedad en la declaración de intenciones, aparece el prólogo autorial posterior que, en 1758, incluye Montesquieu en sus Lettres persanes $(1721)^{11}$, bajo el título de Quelques réflexions sur les Lettres persanes:

En parlant de notre religion, ces Persans ne devaient pas paraître plus instruits que lorsqu'ils parlaient de nos coutumes et de nos usages ; et s'ils trouvent quelquefois nos dogmes singuliers, cette singularité est toujours marquée au coin de la parfaite ignorance des liaisons qu'il y a entre ces dogmes et nos autres vérités (Montesquieu (1758), 1989: 20).

Con una impecable argumentación justificativa ante las críticas que la obra había sufrido en ediciones anteriores, acusada de realizar una sátira política y religiosa, el autor no se limita a satisfacer al censor y a la crítica, sino que pretende que el lector implícito, aquél que unas estructuras y huellas textuales nos permiten reconstruir, se convierta en un lector Ideal, susceptible de interpretar el texto en el sentido que su autor lo concibió y creó. El mensaje implícito de Montesquieu reposa sobre su ambigua declaración de intenciones: "On prie le lecteur de ne pas cesser un moment de regarder les traits dont je parle comme les effets de la surprise [...] Il est prié de faire attention que tout l'agrément consistait dans le contraste éternel entre les choses réelles et la manière singulière, naïve ou bizarre, dont elles étaient aperçues" (Montesquieu (1758), 1989: 21). Y, por si el lector implícito, que en estos momentos ya no es el crítico o el censor, todavía no responde a estos guiños y gestos que el autor le hace de modo velado y ambiguo, añade: "Certainement la nature et le dessein des Lettres persanes est si à découvert qu'elles ne tromperont jamais que

${ }^{11}$ Cuya edición original data de 1721, la cual presentaba un prólogo autorial que no asumía la autoría de la obra (prólogo autorial denegativo). Muchos autores aprovechan ediciones posteriores de sus obras para asumir la paternidad que en un comienzo habían negado con el objeto de valorar la recepción de su obra y escamotearla a la crítica y la censura. 
ceux qui voudront se tromper eux-mêmes" (Montesquieu (1758), 1989: 21). Este único enunciado, gracias a la sutileza y a las estrategias autoriales que hemos reseñado, es capaz por sí solo de actualizarse en varias direcciones, y de influir de manera distinta en distintos tipos de destinatarios, en el lector temido y deseado al mismo tiempo, en el sentido que el autor se propone con cada uno, con independencia de las declaraciones autoriales de intenciones que presenta el mismo enunciado de modo explícito.

\section{La ambigüedad en la definición genérica}

Genette entiende que la función de la definición genérica bien podría considerarse una variante de la de declaración de intenciones. Lo cual es cierto, pero es preciso añadir que, en el marco de la novela que nos ocupa, la definición genérica tampoco puede separarse de la función del prologuista con respecto al texto y su régimen de verdad en el prólogo, ya que, como se ha podido comprobar en el punto a/, la estrategia del autor de aparecer, esconderse o simular ser otro depende del hecho de que reconozca o no la paternidad de la obra y de que ésta sea una historia real o una invención o roman, lo que finalmente viene a definir - por alusión o por negación-, el género que se practica, en una actitud siempre ligada al conflicto realidad/ficción. Pero existen otros casos en los que los prólogos, cuando definen o designan las obras a las que acompañan, lo hacen de un modo también ambiguo, en el sentido no de la contradicción, ni de la polisemia del enunciado, sino más bien como una consecuencia de resultar indecisos, imprecisos, generalizadores, vagos o neutros, en el sentido de que podrían ser muchas cosas, sin ser ninguna en concreto, o tal vez cualquiera salvo roman. En Le Pour et contre, Prévost señala el alcance del problema genérico:

Ce serait d'y opposer un mélange de fictions et de vérités, que leurs auteurs prennent ainsi plaisir à confondre, parce qu'écrivant pour plaire ils savent que la vérité seule ne plaît pas toujours et qu'un récit de pure imagination ne saurait satisfaire non plus les personnes de bon sens. Il est vrai qu'on ne serait guère plus avancé après cette supposition, puisque la difficulté de démêler le vrai du faux empêcherait toujours qu'on ne pût fixer à quelle classe un livre de cette nature appartient. Mais on ne courra jamais grand risque à le placer au rang des romans... (Prévost, 1733-1740: 352353, Vol. 6 de 20 Vols.).

En este sentido, aunque escape al objeto de estas páginas, el análisis de las principales funciones del prólogo autorial original demuestra que, muy a menudo, cuando aparece el término "roman" en él, lo hace desde el punto de vista teórico y preceptivo, de lo que es y lo que debería ser la novela en general, pero no con la función de designar o definir a las obra concreta a la que acompaña, en lo que constituiría su definición genérica. Así pues, el término "roman" o novela, como definición del género al que pertenece cada obra, se constata realmente en escasas ocasiones, lo que suele denotar indecisión e incertidumbre en cuanto a la naturaleza del "roman", que casi siempre debe verse auxiliado por adjetivos tales como "histo- 
rique", "morale" u otros, dependiendo sobre todo de que aparezca en la primera o segunda mitad de siglo respectivamente. Existe una actitud evasiva hacia la propia función de definición genérica de la obra concreta, función que suele delegarse en el lector. Por otro lado, se aprecia que la denominación que más se produce, cuando el autor se refiere a las composiciones que presenta, es la de "ouvrage", y ello con diferencia. En segundo lugar aparece la de "livre" y, en tercer lugar, fórmulas como "ce genre d'écrire" o "le genre dans lequel l'ouvrage est écrit", o "dans quelque genre où l'on écrive", y a estos términos les siguen los de "compositions", "productions", etc. Los términos obra, libro, etc., manifiestan una indeterminación y una opacidad evasiva generalizadora, que evita efectuar una definición concreta, ya que los señalados son conceptos perfectamente aplicables a cualquier género sin aludir a ninguno ya que, en este sentido, son imprecisos y ambiguos. Sin embargo, llama la atención la proliferación de otras denominaciones como, sobre todo, "histoire de", pero también "histoire morale", "mémoires", "récit autobiographique", "confessions", "vies" y "aventures de", etc., ya sean ajenas o propias ${ }^{12}$, en ocasiones mezcladas, como en el caso de Mémoires et aventures d'un homme de qualité qui s'est retiré du monde - Histoire du chevalier des Grieux et de Manon Lescaut, de Prévost. Obviamente, casi nadie nombra el término "roman", palabra casi tabú, vocablo maldito, poco prestigiado y que se había convertido en el punto de mira de la crítica

\footnotetext{
${ }^{12}$ Sin ánimo de exhaustividad, y de manera aleatoria, indico algunos ejemplos: Cléon, ou le petitmaître esprit fort. Anecdote morale; Le Diable amoureux, nouvelle espagnole; Histoire du Prince Apprius, etc., extraite des Fâstes du monde depuis sa création. Manuscrit persan trouvé dans la bibliothèque de Shah-Hussain, roi de Perse, détrôné par Mamouth en 1772. Traduction française par Messire Esprit, gentilhomme provençal, servant dans les troupes de Perse ; Sidney et Volsan, histoire anglaise ; Thérèse philosophe ou Mémoires pour servir à l'histoire du Père Dirrag et de Mademoiselle Éradice; Lettres juives, ou correspondance philosophique, historique et critique, entre un juif voyageur en différents États de l'Europe, et ses correspondants en divers endroits. Nouvelle édition, augmentée de Nouvelles Lettres et de quantité de remarques; Les Illustres Françoises, histoires véritables, où l'on trouve, dans des caractères très particuliers et fort différens, un grand nombre d'exemples rares et extraordinaires. Des belles Manières, de la Politesse, et de la Galanterie des Personnes de l'un et de l'autre Sexe de cette nation; Le colporteur. Histoire morale et critique; Histoire de Madame de Luz. Anecdote du règne d'Henri IV; Les sonnettes ou Mémoires de Monsieur le Marquis D'***; Angola, Histoire indienne, ouvrage sans vraisemblance; Histoire nouvelle et divertissante du bonhomme Misère ; Les Liaisons dangereuses ou Lettres recueillies dans une société et publiées pour l'instruction de quelques autres; Nouvelles Aventures de l'admirable Don Quichotte de la Manche, composées par le licencié Alonso Fernandez de Avellaneda et traduites de l'espagnol en français pour la première fois ; Journal d'un Espagnol; Mémoires et aventures d'un homme de qualité qui s'est retiré du monde - Histoire du chevalier des Grieux et de Manon Lescaut; Manuscrit trouvé à Saragosse; Le Doyen de Killerine. Histoire morale; Le monde moral, ou Mémoires pour servir à l'histoire du cour humain; Histoires galantes, nouvelles et véritables par M. le Chevalier de R. C. D. S. ; Les crimes de l'amour, nouvelles hérö̈ques et tragiques; Contes Moraux dans le goût de ceux de M. Marmontel ; Les Surprises, ou l'histoire de la jeunesse de Mme de Bonval écrite par ellemême, et rédigée par M. Y., etc.
} 
y censura. Así es como Jan Herman lo analiza en su Introduction générale : ceci n'est pas un roman:

Genre en mal de légitimité, rejeté à la périphérie du système, qui pose un problème d'auctorialité, le roman, en effet, ne semble pouvoir subsister qu'en s'effaçant comme genre littéraire - jusqu'à supprimer son appellation générique - et au travers d'un désaveu d'auctorialité : l'auteur d'un discours sans légitimité comme le roman ne s'avoue pas, il ne se fait pas reconnaître et ne reconnaît pas son texte. Le lieu de ce désaveu de responsabilité est la Préface [...] La Préface de roman, au dix-huitième siècle se fait reconnaître comme une composition ambiguë... (Herman et al., 2008: 5)

Por oposición, se observa un gusto general por la definición genérica cuando se trata por ejemplo del cuento, siempre acompañado de un elogio del mismo, mientras que en cambio, cuando se trata de novelas, la tendencia es la no-definición, utilizando los subterfugios de infinidad de historias, aventuras, memorias, etc., de fondo histórico, que proceden de manuscritos encontrados, correspondencias, cuadernos, etc., que llegan al prologuista por azar, y que ven modificado su original canal del proceso comunicativo, ya que realmente no les estaban destinados a quienes los encuentran, y tampoco al lector que finalmente lee la obra. De este modo, ocultando el origen de composición de la obra, este recurso adquiere cierto carácter de pre-existencia o realidad antes de que el prologuista entre en posesión de la misma. También se trata de relatos contados por otros, que el prologuista intercepta de modo ilícito, en los que siempre se trata de historias pretendidamente ajenas que existen con independencia de quien las presenta. $\mathrm{Y}$ en los escasos casos en los que se reconoce abiertamente que se trata de fictions, tampoco se utiliza el término "roman" novela, menospreciada a comienzos de siglo y arrastrando los lastres de la novela barroca anterior, y en continua búsqueda y evolución hasta finales del mismo, puesto que se trata de un género que carece de la normalización y el prestigio clásicos, como señala Fr. Barguillet: "sans parrainage antique" (Barguilllet, 1981: 36), que padece todos los males estilísticos, por lo que es preciso hacer de ella algo digno, antes de reconocer o definir las obras con un término tan polémico y, lógicamente, desacreditado. Paradójicamente, la no-definición genérica de las obras que se constata en los prólogos, coexiste con un importante esfuerzo teórico y preceptivo por parte de los autores por definir lo que deben ser las novelas en general, de ahí que abunde el prólogo preceptivo. Sin embargo, con respecto a la obra concreta

\footnotetext{
${ }^{13}$ Es, precisamente, este conflicto el que mueve a J. Herman a adoptar su fórmula de roman véritable, que justifica del siguiente modo: "Le Nouveau paradigme romanesque a besoin de se donner un statut épistémologique ambigu, parce qu'à travers le besoin d'accréditer le récit par la réduction de son aspect fictif transparaît une seconde nécessité qui consistait à légitimer le récit en présentant les vérités qu'il véhicule comme fictives. Ce nouveau paradigme littéraire est celui du roman véritable" (Herman et al., 2008: 54).
} 
que introducen, su definición es casi siempre ambigua: cuando no se niega que se trate de una novela, se elude la cuestión, dejando al albur del lector que cada cual piense lo que quiera y, preferiblemente, que no se trata de una novela, al menos no lo que hasta el momento se ha entendido por "roman". Será preciso cambiar el contenido semántico de este signo, y que el público sea capaz de descodificarlo de otro modo -objetivo que se propone y llevan a cabo los prólogos justificativo y preceptivo- para acuñarlo en un nuevo sentido, para que sea actualizado de modo distinto.

\section{La ambigüedad en el contrato de ficción.}

Una de las funciones más importantes y características del prólogo de la novela francesa del siglo XVIII consiste en llevar a cabo un contrato de ficción, por el cual el autor deja claro que en su obra no se alude a personas conocidas y concretas reales, que no se trata de una historia con claves en sus personajes, frente a la sospecha por parte del lector, censores, críticos o presuntos aludidos, de que la pintura del cuadro de la sociedad contemporánea pudiera implicar ciertas referencias auténticas: se trata de lo que los autores de la época denominan faire des applications. Con objeto de defenderse contra la acusación de dichas alusiones a personas reales, los autores suelen utilizar un argumento preventivo y neutralizador, mediante el que declaran que es inútil identificar a sus personajes con personas de la realidad, puesto que en la obra no se va a encontrar sino personajes de ficción: se trata de un fenómeno que abunda en el prólogo de la novela francesa del XVIII y llega hasta nuestros días. Sin embargo, en este momento únicamente me interesa destacar la aplicación de la estrategia de la ambigüedad a esta cuestión. ¿Es cierto que, como dicen los autores, es inútil buscar dichas aplicaciones? Si lo es, si tan evidente resulta, ¿por qué prevenir al lector contra ellas? ¿No se trata, más bien, de estimular la curiosidad del lector, su interés por la obra, incluso el cuidado y el detenimiento en la lectura que se le propone, mediante un subterfugio estratégico que provoca al lector para que entienda lo contrario de lo que se le dice? ¿Cómo, después de semejante prevención por parte del autor, no se va a sentir provocada la inteligencia del lector para encontrar mil ejemplos que demuestren que, $a$ él, el autor no le engaña, puesto que él sabe muy bien a quién se alude detrás de la fachada de tal o cual personaje?

Un ejemplo muy elocuente de esta peculiar y estratégica modalización ambigua de las declaraciones que niegan la existencia de referencias reales y, al mismo tiempo incitan a buscarlas, lo constituye el prólogo de Prévost a su Histoire d'une Grecque Moderne (1740):

Celle-ci ne servira qu'à déclarer au lecteur qu'on ne lui promet, pour l'ouvrage qu'on lui présente, ni clé des noms, ni éclaircissement sur les faits ni le moindre avis qui puisse lui faire comprendre ou deviner ce qu'il n'entendra point que par ses propres lumières... [...] On ne dissimulera pas néanmoins qu'il peut avoir un double prix pour ceux qui auront eu quelque connaissance des principaux personnages... (Prévost (1740), 1989: 19). 
Este double prix al que alude Prévost, va referido al doble nivel de lectura que, dependiendo del lector, puede presentar su mensaje. El autor deja claro que existen diversas interpretaciones profundas en una única representación aparente - o superficial. De este modo, cada lector debe escoger su propio nivel de profundidad, pero el autor siempre podrá argüir que, si prefiere la más escabrosa u osada, la responsabilidad de ello recaerá sobre el propio lector, no sobre el autor.

Otro ejemplo de la estrategia de ambigüedad aplicada a esta peculiar función prefacial que Genette califica como contrato de ficción, lo constituye el prólogo de Le Colporteur (1761), de Chévrier:

J'ai nommé beaucoup de monde dans Le Colporteur, et j'ai suivi en cela l'exemple des satiriques romains et français. Si je n'ai pas leurs talents, ... [...] Mais j'ai eu le soin honnête de ne désigner en mal que des personnes affichées par leur mauvaise conduite, ou par l'avilissement de leur état ; ceux dont les noms exigent des ménagements y portent des titres masqués ; mais si je suis parvenu à les peindre d'après nature, le public les reconnaîtra, et me lavant alors de l'application, je dirai au lecteur ce que disait Phèdre à Enone : "C'est toi qui l'as nommé" (Chévrier (1761), $1993: 754)$.

Resulta difícil llevar el texto a un nivel más elevado de ambigüedad. ¿Será quizás una buena prueba de que los prólogos no sabrían renunciar a ella? Este prólogo evidencia y subraya el uso de un doble mensaje por parte de los autores que se proponen con un único enunciado neutralizar la crítica ("se laver de l'application"), al tiempo que incitan al lector a buscar unos rostros reales tras las distintas anécdotas, esto es, le incitan a "faire des applications" y a desconfiar o romper el contrato de ficción. Además de cumplir esta doble finalidad, existe otra cuestión no menos importante: el placer de la lectura, en una vertiente que puede calificarse como de lectura social, es decir, compartida, placer que se incrementa considerablemente por el aspecto satírico y crítico de la pintura de los vicios de seres reales-idesvelar los vicios ajenos forma parte de la condición humana!-, y por el aspecto lúdico que se puede añadir a la interpretación de los términos del contrato de ficción. Todo lo cual concurre para que el lector entienda que lo que el autor habría querido decir es algo parecido a lo siguiente: ;Ojo a lo implícito! me es imposible facilitar claves, $n i$ pistas, pero no dejen de buscarlas porque es posible que las encuentren... en su imaginación al menos. Y créanme: cuantas más applications encuentre Vd., más inteligente le creeré y tanto mejor será la lectura que haga de mi obra. Ciertamente, todo depende de la astucia o de la malicia del lector al que, en este mismo sentido, Montesquieu en sus Lettres persanes (1721), en el prólogo a la edición de 1758 señala: "Certainement la nature et le dessein des Lettres persanes sont si à découvert qu'elles ne tromperont jamais que ceux qui voudront se tromper eux-mêmes"14 (Montesquieu (1758), 1989: 21).

\footnotetext{
${ }^{14}$ Se trata además de una interesante llamada del autor al lector en lo que ya no es un contrato de
} 
Como ha podido verse, aparece una contradicción en los enunciados de los ejemplos citados: por un lado, se declara que no existen alusiones a personajes reales pero, por otro, la modalización ambigua del discurso provoca e incita al lector para que las encuentre aunque, de todos modos, lo importante en el plano de la lectura sea que las busque. De este modo, el autor se propone satisfacer a los distintos lectores implícitos, al que se sienta reflejado y pueda censurar la obra o al que simplemente espera divertirse con las aplicaciones concretas de vicios y ridículos. Gracias al recurso de la ambigüedad, se produce un discurso polisémico, mediante el cual una única propuesta autorial responde a intereses o deseos distintos. De tal manera que ese juego entre lo explícito y lo implícito, que responde a una tensión entre la realidad y el deseo y a otra, no menos importante, entre lo oculto y lo desvelado, conduce a los lectores a aceptar el juego del autor, dando por muy eficaz una estrategia de la ambigüedad que permite que un mismo enunciado pueda presentar varios niveles de lectura o apunte a distintos lectores implícitos con sus propios y diversos horizontes de expectativas. Todo ello sin contar que, tal y como hemos visto, resulta un modo sutil, eficaz y certero de aumentar el interés y placer de la lectura.

\section{Conclusión}

En síntesis, como ha podido observarse, en estos prólogos de la novela francesa del XVIII la ambigüedad responde a unos claros propósitos pragmáticos. Para conseguirlos, los autores adoptan una peculiar modalización discursiva, de carácter estilístico, ya que el análisis de la ambigüedad de estos prólogos, evidencia tanto el valor literario de esta escritura prefacial, como el alarde técnico y artístico de estos prologuistas. Por otro lado, esta práctica de la ambigüedad se define como una estrategia autorial altamente eficaz y rentable, y su peculiar modalización la convierte en una de las estrategias autoriales más sofisticadas y sutiles. Por todo ello, y en consecuencia, la estrategia de la ambigüedad que caracteriza al prólogo de la novela francesa del XVIII resulta ser también un valioso indicio de los conflictos o dilemas que sufre el género novelesco en la época, y los enunciados ambiguos que acabamos de ver toman la forma de un rompecabezas que permite reconstruir la propia historia o evolución de la novela a lo largo de siglo.

ficción, sino más bien un contrato o pacto de lectura, que correspondería a la función del prólogo de cómo debe leerse la obra, esto es, el orden de lectura: de comienzo a fin, en el orden de sus capítulos. En este caso, además, Montesquieu añade: y con mucha atención hacia lo implícito. 


\section{REFERENCIAS BIBLIOGRÁFICAS}

Textos del siglo XVIII

Chévrier, F.-A., (1993) Le colporteur. Histoire morale et critique. $1^{\mathrm{e}}$ édition 1761, in Romans libertins du XVIII $I^{\text {eme }}$ siècle, Paris, Robert Laffont, Coll. Bouquins.

Laclos, P.-A.-F. Ch. de, (1979) Les Liaisons dangereuses ou Lettres recueillies dans une société et publiées pour l'instruction de quelques autres. $1^{\mathrm{e}}$ édition 1782, in Laclos, P.-A.-F. Ch. de, Euvres Complètes, Paris, Gallimard, Bibliothèque de la Pléiade.

Marivaux, P.-C. Ch. de, (1972) Le Télémaque travesti. $1^{\mathrm{e}}$ édition 1736, in P.-C. Ch. de, Marivaux: Euvres de jeunesse, Paris, Gallimard, Bibliothèque de la Pléiade.

Monbron, Fougeret de, (1993) Margot la Ravaudeuse. $1^{\mathrm{e}}$ édition 1748, in Romans libertins du XVIII ${ }^{\text {ème }}$ siècle, Paris, Robert Laffont, Coll. Bouquins.

Montesquieu, Ch.-L. de Secondat, barón de, (1989) Lettres persanes. $1^{\mathrm{e}}$ édition 1721, Paris, Presses Pocket.

Prévost, A.-F., Abbé de, (1733-1740) Le Pour et Contre. 20 volumes, tome 6, Paris, Firmin Didot.

Prévost, A.- F., Abbé de, (1989) Histoire d'une Grecque moderne. $1^{\mathrm{e}}$ édition 1740, Grenoble, Presses Universitaires de Grenoble.

Prévost, A.- F., Abbé de, (1977) Le Philosophe anglais ou Histoire de Monsieur Cleveland, fils naturel de Cromwell. $1^{\mathrm{e}}$ édition 1731, in Prévost, A.- F., Abbé de, Euvres.Volume II, Grenoble, Presses Universitaires de Grenoble.

Restif de la Bretonne, N.-E., (1960) Les nuits de Paris ou le spectateur nocturne. $1^{\mathrm{e}}$ édition 1788, Paris, Firmin Didot.

Restif de la Bretonne, N.-E., (1972) La paysanne pervertie ou les dangers de la ville. $1^{\mathrm{e}}$ édition 1784, Paris, Garnier-Flammarion.

Restif de la Bretonne, N.-E., (2002) La jolie solliciteuse. $1^{\mathrm{e}}$ édition 1785, in Nouvelles du XVIII ${ }^{\text {eme }}$ siècle. Paris, Gallimard, Bibiothèque de la Pléiade.

Rousseau, J.-J., (1967) Julie ou la nouvelle Héloïse. Lettres de deux amants habitants d'une petite ville au pied des Alpes. $1^{\mathrm{e}}$ édition 1761, Paris, GarnierFlammarion.

Rustaing de Saint-Jory, L. (atribuido a), (2002) Histoires galantes, nouvelles et véritables par M. le Chevalier de R. C. D. S. $1^{\mathrm{e}}$ édition 1720, in Nouvelles du $X_{V I I I}{ }^{e ̀ e}$ siècle. Paris, Gallimard, Bibliothèque de la Pléiade.

Sade, D.-A.-F. de, (1967) Eugénie de Franval. $1^{\mathrm{e}}$ édition 1788, in Sade, D.-A.-F. de, Les Crimes de l'Amour. Paris, Les Éditions de la Renaissance, Club Géant.

Sade, D.-A.-F. de, (1995) Justine ou les Malheurs de la Vertu. $1^{\mathrm{e}}$ édition 1788, in Sade, D.-A.-F. de, Euvres. Paris, Gallimard, Bibliothèque de la Pléiade. 
Salverte, A.-J. E. de, (2003) Un pot sans couvercle et rien dedans. $1^{\mathrm{e}}$ édition 1799 , in Angelet, Ch, Recueil de préfaces de Romans du XVIII siècle. Volume II, Leuven, Publications de l'Univiversité de Saint-Étienne - Presses Universitaires de Louvain, Coll. Lire le Dix-huitième Siècle.

Voisenon, Cl.-H. F. Abbé de, (1993) Histoire de la félicité. $1^{\mathrm{e}}$ édition 1751, in Romans libertins du XVIII ${ }^{\text {eme }}$ siècle, Paris, Robert Laffont, Coll. Bouquins.

Obras consultadas

Barguillet, F., (1981) Le Roman au XVIII'me siècle. Paris, PUF.

Bleger, J., (1967) Simbiosis y ambigüedad. Estudio psicoanalítico. Buenos Aires, Paidós.

Colloque Clermont-Cologne, (1984) L'ambiguïté. Actes du Colloque ClermontCologne. Clermont-Ferrand, Université Clermont II.

Dürrenmatt, J., (2001) Le vertige du vague: les Romantiques face à l'ambiguïté. Paris, Kimé.

Empson, W., (1995) Seven Types of ambiguity. London, Penguin Books.

Genette, G., (1987) Seuils. Paris, Seuil, Coll. Poétique.

Gutierrez, Cl., (1977) "Ambigüedad y comunicación" in Revista Latinoamericana de Filosofia. N NIII [En línea] Disponible en: www.claudiogutierrez.com/Ambigued ad.html).

Herman, J.; Kozul, M. \& N. Kremer, (2008) Le Roman véritable. Stratégies préfacielles au XVIII siècle. Oxford, SVEC, Voltaire Foundation.

L'ambiguïté, (1992) Caliban. NXXIX, Université Toulouse-Le Mirail.

Landheer, R., (1984) Aspects linguïstiques et pragmatico-rhétoriques de l'ambiguitté. Tesis doctoral. Holanda, Université de Leyden.

Pergnier, M., (1990) "L'ambiguité de l'ambiguité" in Lederer, M. (éd.), Mélanges D. Seleskovitch. Paris, Lettres Modernes, pp. 17-28.

Velázquez, J. I., (2008) "L'ambigüité et ses effets dans La Double inconstance" in Revue des Sciences Humaines ("Marivaux moderne et libertin »). № 291, pp. 77.

Velázquez, J. I., (2005a) "Análisis de los efectos de ambigüedad en la literatura contemporánea francesa (I)" in Montesa Peydró, S., (coord.), A zaga de tu huella (Homenaje al Prof. C. Cuevas), T. II. Málaga, Universidad de Málaga, pp. 727- 739.

Velázquez, J. I., (2005b) "Análisis de los efectos de ambigüedad en la literatura contemporánea francesa (II)" in Desprès Caubrière. C. (coord.), Homenaje al Prof. Francisco J. Hernández. Valladolid, Universidad de Valladolid, pp. 677-690.

Velázquez, J. I., (2007) "La ingenua libertina y la ambigüedad como expresión del erotismo" in Vázquez, L. \& Laniez G. (eds.), Colette universal. Castellón, Univiversitat Jaume I, pp. 149-168. 
Velázquez, J. I., (2004) "Les demi-vierges de Prévost: tres apuntes de análisis" in Ozaeta, Ma R.; Popa, D. \& A. Yllera (eds.), Palabras y recuerdos (Homenaje a Rosa $M^{a}$ Calvet). Madrid, U.N.E.D., pp. 219-226.

Zawisza, E., (1977) "Sur le discours préfacier dans les romans du XVIII ${ }^{\text {eme }}$ siècle" in Acta Universitatis Wratislaviensis. № 319, pp. 89-104. 